УДК 339.92

\title{
Сергей СУТЫРИН
}

Ирина ВОРОББЕВА

\section{КРУПНЫЕ ФИНСКИЕ КОМПАНИИ НА РОССИЙСКОМ РЫНКЕ}

\begin{abstract}
Аннотация. В статье приводятся результаты исследования деятельности крупных финских компаний в России. Представлен анализ основных показателей их функционирования и выделены наиболее существенные факторы, оказавшие влияние на результаты работы. Подробно рассмотрен опыт деятельности на российском рынке двух успешных крупных финских компаний и компании, принявшей решение об уходе из России. Сделан вывод, что факторы успеха крупных финских компаний в России непосредственно связаны с адаптацией к изменяющимся условиям и локализацией хозяйственной деятельности. В число лидеров выходят те, кто умело сочетает конкурентные преимущества производства в России со своими внутренними специфическими ресурсами и возможностями, грамотно реагируя на отраслевую конкуренцию и институциональные особенности ведения бизнеса в РФ.

Ключевые слова: Финляндия, Россия, крупный бизнес, выход на внешний рынок, факторы успеха, уход с рынка.
\end{abstract}

\section{Введение}

Цель данной статьи состоит в выявлении и сравнительном анализе результатов стратегических решений о деятельности на российском рынке на современном этапе ряда крупных финских компаний.

Эмпирическую базу исследования составили данные национальной статистики, годовые отчёты компаний, публикации в открытых источниках массовой информации, в том числе интервью ведущих менеджеров. При анализе деятельности крупных финских фирм в России использованы результаты исследований интернетиздания “Фонтанка.ру” и опросов, проводившихся Финско-Российской торговой палатой.

(C) Сутырин Сергей Феликсович - доктор экономических наук, профессор, зав. кафедрой мировой экономики, Санкт-Петербургский государственный университет (СПбГУ). Адрес: 199034, Россия, Санкт-Петербург, Университетская наб., 7/9. E-mail: s.sutyrin@spbu.ru; s.sutyrin@ hotmail.com

Воробъева Ирина Валентиновна - кандидат экономических наук, доцент кафедры мировой экономики, Санкт-Петербургский государственный университет (СПбГУ). Адрес: 199034, Россия, Санкт-Петербург, Университетская наб., 7/9. E-mail: i.vorobieva@ spbu.ru; irinavorob@mail.ru

Исследование выполнено при финансовой поддержке РФФИ и Академии общественных наук Китая в рамках научного проекта № 19-51-93009.

DOI: http://dx.doi.org/10.15211/soveurope32019125138 


\section{Обзор литературы}

Значимость экономических отношений России и Финляндии обусловливает внимание к их изучению со стороны российских и зарубежных ученых [Пискулов, 2013; Шлямин, 2007, 2015; Волков, 2016; Liuhto, 2011; Sutela, 2007 и др.]. В частности, Реколайнен [Реколайнен, 2018] показывает, что российско-финляндское сотрудничество развивается в различных областях, и, несмотря на проблемы, с которыми сталкиваются финские фирмы в России, большая часть крупных компаний пришла на российский рынок с долгосрочными намерениями. Рассматривая опыт и направления трансграничного сотрудничества, Ковалев [Ковалев, 2014] обращает внимание на развитие связей малых и средних предприятий (МСП), государственных учреждений и неправительственных организаций. Проблемы и возможности выхода финских МСП на российский рынок в условиях изменений политической и бизнес-среды отражены в исследовании Зашева и Трофименко [Зашев, Трофименко, 2017], барьеры такого выхода раскрываются в статье Зашева и Сутырина [Zashev, Sutyrin, 2012].

Сравнительная значимость институциональных, отраслевых и корпоративных факторов при выборе конкретных форм инвестирования финских компаний в Россию оценивается в статье Кархунен и Косонен [Кархунен, Косонен, 2009]. В ряде публикаций рассмотрены стратегии интернационализации отдельных крупных финских фирм, среди них KONE [Маршан, 2004], Stockmann, S-Group, K-Group [Larimo, Huuhka, 2007], Kemira [Golikova et al., 2011], Fortum, Neste [Zimin, 2012], Valio [Бухвалов, Алексеева, 2015].

В то же время в экономической литературе ощущается недостаток исследований того, как сегодня “чувствуют" себя в России крупные по меркам Финляндии компании, принявшие стратегическое решение о развитии бизнеса на российском рынке. Кому из них и как удается успешно функционировать? Каким фирмам пришлось уйти с российского рынка и какие факторы оказали на это основное влияние? Дать ответ на эти и аналогичные вопросы важно и с теоретической, и с практической точек зрения.

\section{Общее состояние и результаты деятельности финских компаний}

На российском рынке работает около 900 компаний с участием финляндского капитала ${ }^{1}$. Крупный бизнес страны Суоми сегодня представлен практически во всех регионах России. При этом наибольшее количество компаний ведёт деятельность в Санкт-Петербурге и Ленинградской области, Москве и Московской области, а также в целом в Северо-Западном и Центральном федеральных округах. Это объясняется, в частности, географической близостью, благоприятным инвестиционным климатом и более высоким потребительским спросом. Многие крупные фирмы начинали свой бизнес в Санкт-Петербурге и затем распространили деятельность на другие субъекты РФ. В таблице 1 представлены данные о 15 финских компанияхлидерах, ранжированные по выручке, полученной в России в 2017 г.

Следует особо отметить, что в 2017 г. у большей части представленных в таблице 1 фирм отмечалась положительная динамика выручки. Правда, темпы её прироста замедлились у половины из них. Объём накопленных инвестиций фирм, ос-

1 “Финский бизнес - 2018”, URL: https://www.fontanka.ru/longreads/finnish_business_2018/ (дата обращения: 28.03.2019).

Современная Европа, 2019, №3 
новной сферой деятельности которых является производство (именно они доминируют в топ - 15), на конец 2017 г. составил 7,8 млрд евро.

Таблица 1.

Крупнейшие финские компании в России

\begin{tabular}{|c|c|c|c|c|c|c|}
\hline \multirow[t]{2}{*}{ № } & \multirow[t]{2}{*}{ Компания } & \multirow{2}{*}{$\begin{array}{c}\text { Основная сфера } \\
\text { деятельности }\end{array}$} & \multirow{2}{*}{$\begin{array}{l}\text { Выручка } \\
2017, \\
\text { млрд руб. }\end{array}$} & \multicolumn{2}{|c|}{ Изменение выручки } & \multirow{2}{*}{$\begin{array}{c}\text { Размер инве- } \\
\text { стиций на } \\
\text { конец } 2017 \text {, } \\
\text { млн евро }\end{array}$} \\
\hline & & & & $\begin{array}{c}2017 \text { к } \\
2016, \%\end{array}$ & $\begin{array}{c}2016 \text { к } \\
2015, \%\end{array}$ & \\
\hline 1 & Fortum & производство & 72,3 & 9,0 & 10,2 & 5400 \\
\hline 2 & YIT & недвижимость & 27,7 & 30,0 & 10,2 & 418 \\
\hline 3 & $\begin{array}{l}\text { Nokyan } \\
\text { Tyres }\end{array}$ & производство & 21,7 & 31,5 & 5,9 & 964 \\
\hline 4 & Stora Enso & производство & 19,7 & $-4,8$ & 15,8 & 310 \\
\hline 5 & Neste & ретейл & 19,0 & 3,3 & 4,4 & 215 \\
\hline 6 & UPM & производство & 15,3 & 0,7 & 6,2 & 200 \\
\hline 7 & Fazer & производство & 12,4 & $-5,3$ & 3,2 & 300 \\
\hline 8 & K-Group & ретейл & 12,1 & $-56,8$ & 1,7 & $465^{*}$ \\
\hline 9 & $\begin{array}{l}\text { SOC (Socos, } \\
\text { Prisma) }\end{array}$ & ретейл & 11,9 & $-0,8$ & $-5,5$ & 220 \\
\hline 10 & Tikkurila & производство & 10,5 & 6,1 & 3,5 & 134 \\
\hline 11 & Posti (Itella) & $\begin{array}{c}\text { логистика и } \\
\text { дистрибуция } \\
\end{array}$ & 7,8 & 0,9 & $-5,5$ & 459 \\
\hline 12 & Huhtamäki & производство & 7,0 & 9,8 & 26,7 & 120 \\
\hline 13 & Valio & производство & 5,98 & 10,7 & 22,7 & 65 \\
\hline 14 & Aspo & $\begin{array}{l}\text { логистика и } \\
\text { дистрибуция }\end{array}$ & 5,91 & 0,2 & 20,5 & 16 \\
\hline 15 & Atria & производство & 5,6 & 5,7 & 4,3 & 283 \\
\hline
\end{tabular}

*на сентябрь 2017 г.

Источник: составлено по данным “Лидеры финского бизнеса - 2017”, URL: https://www.fontanka.ru/longreads/business_fi/; “Финский бизнес - 2018”, URL: https://www.fontanka.ru/longreads/finnish_business_2018/ (дата обращения: 28.03.2019).

Для оценки факторов, влияющих на деятельность финских компаний в России, обратимся к исследованиям Финско-Российской торговой палаты. Результаты опроса представителей 277 фирм, проведённого осенью 2018 г. ${ }^{1}$, в целом свидетельствуют о сохранении интереса к нашей стране. Треть респондентов отметила положительную динамику своего бизнеса, половина - оценила своё положение как стабильное. Экспорт в Россию вырос у $28 \%$ финских компаний, ещё у $33 \%$ остался на прежнем уровне. Аналогична оценка перспектив развития в краткосрочном периоде: планировали рост бизнеса $45 \%$ респондентов, готовились к сокращению только $12 \%$.

${ }^{1}$ Барометр финско-российской торговли, URL: https://www.svkk.ru/wpcontent/uploads/sites/2/2018/11/\%D0\%91\%D0\%B0\%D1\%80\%D0\%BE\%D0\%BC\%D0\%B5\%D $1 \% 82 \% \mathrm{D} 1 \% 80-\% \mathrm{D} 0 \% \mathrm{BE} \% \mathrm{D} 1 \% 81 \% \mathrm{D} 0 \% \mathrm{~B} 5 \% \mathrm{D} 0 \% \mathrm{BD} \% \mathrm{D} 1 \% 8 \mathrm{C}-2018 . \mathrm{pdf}$ (дата обращения: 28.03.2019).

Современная Европа, 2019, №3 
Число компаний с инвестиционными намерениями составило только пятую часть опрошенных. Здесь существенных изменений по сравнению с более ранними исследованиями не наблюдалось. Многие компании адаптировались к сложившейся геополитической ситуации и занимают выжидательную позицию в отношении дальнейших инвестиций.

Среди проблем, оказывающих влияние на бизнес компаний в России, респонденты выделили и экономические, и политические факторы. На результаты функционирования влияют состояние российской экономики в целом, темпы экономического роста и непосредственно связанный с ними спрос. Так, проблему спроса как одну из наиболее острых отметили почти четверть финских предпринимателей. И это не случайно. Как известно, начиная с 2014 г., наблюдается тенденция к снижению реальных доходов населения РФ. Более того, индекс Джини в последние годы составляет 0,41, что свидетельствует о высокой степени неравенства в распределении доходов. Прослеживалась значительная дифференциация и между регионами страны. По данным Росстата в 2018 г. россияне получали заработную плату в среднем 43445 руб., в Москве она была 79680 руб., Санкт-Петербурге - 56 586 руб. При этом численность населения с денежными доходами ниже прожиточного минимума выросла с 10,7\% в 2012 г. до 13,2 \% в 2017 г. ${ }^{1}$

Снижение располагаемого дохода и рост цен на импортные товары привели к отказу или отсрочке покупки непродовольственных товаров и снижению продаж продуктов питания. Всё больше потребителей отдают предпочтение дешёвым брендам или “безымянным продуктам”.

На результатах деятельности финских компаний на потребительском рынке сказались и долгосрочные тренды изменения потребительского поведения россиян [Sutyrin, Vorobieva, 2017]. Опыт, накопленный ими за годы формирования рыночной экономии в России, стимулирует большее внимание к товарам местного производства. Прежде всего это относится к продуктам питания.

Рост разнообразия на рынке, его насыщение и жёсткая конкуренция предъявляют повышенные требования к предлагаемой продукции. Потребители, особенно представители молодого поколения, ожидают от покупки новых идей и впечатлений. Отметим формирование сегмента “зелёных потребителей”, делающих акцент на здоровом образе жизни и безопасности продуктов. Данный сегмент формирует молодежь, особенно пары с детьми, а также люди с доходами выше среднего, проживающие в крупных городах. Изменение торговой инфраструктуры в России имеет следствием появление новых форматов розничной торговли, выбор места для покупки становится одним из ключевых в модели принятия решений.

Большое значение имеют и политические риски, возросшие для финских компаний с 2014 г. в связи с событиями на Украине. В первую очередь, речь идёт о введенных или “ожидаемых” антироссийских санкций со стороны США и других

\footnotetext{
${ }^{1}$ Росстат. Распределение общего объема денежных доходов и характеристики дифференциации денежных доходов населения, URL:

www.gks.ru/free_doc/new_site/population/urov/urov_32g.doc; Рынок труда, занятость и заработная плата, URL:

http://www.gks.ru/wps/wcm/connect/rosstat_main/rosstat/ru/statistics/wages/;

Численность населения с денежными доходами ниже величины прожиточного минимума и дефицит денежного дохода, URL:

www.gks.ru/free_doc/new_site/population/urov/urov_51g.doc (дата обращения: 28.03.2019).

Современная Европа, 2019, №3
} 
западных стран, а также ответных мерах со стороны нашей страны. Всё это влияет и на перспективы внешнеторговой и инвестиционной деятельности в России.

Для детального анализа деятельности финских компаний на российском рынке были выбраны две крупные динамично развивающиеся в последние годы компании с производственной деятельностью в России (Nokyan Tyres и Valio) и крупная торговая компания (K-Group), принявшая решение о выходе из России в 2018 году.

\section{Valio}

Концерн Valio - ведущий финский производитель, на производственных мощностях которого перерабатывается 80\% всего молока местных фермеров. Владельцами Valio Оу являются 17 финских кооперативов-производителей. В состав концерна входят дочерние компании в России, Швеции, странах Балтии, США и Китае. На долю Valio приходится четверть финского экспорта продуктов питания. В 2017 г. чистая выручка концерна составила 1,7 млрд евро. Общее количество сотрудников по всему миру $-4,1$ тыс. человек ${ }^{1}$.

Основание российского подразделения ООО "Valio" в Санкт-Петербурге в 1994 г. ознаменовало начало современной деятельности концерна в России. Его проникновению на российский рынок сегодня отчасти способствует узнаваемость бренда плавленого сыра Viola, знакомого потребителям ещё с времён CCCP и традиционно воспринимавшегося как высококачественный продукт.

Основная часть производственных площадей концерна находится в Финляндии. Кроме них он владеет двумя заводами в Эстонии. Единственный завод концерна в России был построен в 2006 г. в Ершово (Московская область). Сегодня он специализируется на производстве сыра брендов Viola и Oltermani. Инвестиции в данный проект превысили 60 млн евро.

Несмотря на наличие производственных мощностей, до 2014 г. "Valio" являлся одним из ведущих экспортёров молочной продукции в РФ. Она долгое время была основным экспортным направлением, на которое приходилась почти половина экспорта концерна и пятая часть выпускаемой им в Финляндии продукции.

После введения Россией запрета на импорт молочной продукции из ряда ведущих стран Запада большинство продуктовых линеек продукции Valio оказалось под эмбарго. Для сохранения доли рынка концерну пришлось увеличить объёмы производства в РФ [Liuhto, Sutyrin, Blanchard, 2017]. Задействовали и мощности своего завода, и производство продукции под этим брендом по контракту. В октябре 2014 г. стартовало производство молока и сливок на базе партнёрской компании "Галактика" в Ленинградской области, дополнившее продуктовую линейку питьевого йогурта. В 2017 г. в ассортимент включили сметану. В Московской области в 2015 г. запущено производство йогурта и сыра на мощностях немецкого завода Ehrmann. Площадкой для производства сливочного масла стала Kochmeister Rus.

Круг партнёров и ассортимент выпускаемой по контракту продукции расширялся и в последующие годы. Одновременно направлялись инвестиции для роста объема выпуска собственного завода в Ершово. Сейчас 90\% продаваемых на российском рынке продуктов Valio производится в России. Концерн планирует увеличивать выпуск, хотя признаёт, что невозможно заменить на местное производство весь ассортимент, существовавший до введения санкций. Так, в концерне предъявляются высокие требования к качеству молока. Поэтому сотрудничать с ним могут

${ }^{1}$ Официальный сайт Valio, URL: https://www.valio.com (дата обращения: 28.03.2019).

Современная Европа, 2019, №3 
только поставщики, прошедшие аттестацию по единым стандартам качества компании, которые жёстче российских ${ }^{1}$. Ими стали хозяйства из Ленинградской и Ярославской областей. Их сотрудники прошли обучение на фермах Valio в Финляндии.

В Россию концерн экспортирует из Финляндии безлактозные молоко, сыр и мороженое. Переносить их производство нет необходимости и по финансовым соображениям, и по причине того, что эмбарго не распространяется на такие продукты. Кроме того, на российский рынок концерн поставляет сухие смеси финского детского питания Valio Baby®, соки и ягодные супы, также не включённые в санкционный список. Результаты деятельности этой компании в России можно считать успешными. В 2017-2018 гг. концерн занимал 12-е место среди финских компанийлидеров на российском рынке (таблица 1). Даже после снижения темпов прироста выручки в 2017 г. этот показатель был в 2,5 раза выше, чем по концерну в целом $(4,3 \%)$. На российский рынок приходилось $35 \%$ совокупной выручки.

Более того, у компании есть резервы дальнейшего роста. Доля Valio на российском рынке молочных продуктов, достигнув минимума в 2015 г., стала расти и в 2017 году составила 2\%. На рынке Санкт-Петербурга она составляла 16,5\%. Соответствующие цифры в 2013 г. равнялись 5,95\% и 29,5\%2.

Отметим, что, инвестируя в Россию, компания создавал новые рабочие места. На предприятии в Ершово занято более 200 чел., в целом на российском рынке на конец 2017 г. - 399 чел. Учитывая занятых на контрактных производствах у российских поставщиков молока, последняя цифра будет ещё больше.

Среди факторов успеха Valio в России, наряду с локализацией производства, инвестициям в собственное и контрактное производство, выделим расширение продуктовой линейки за счёт местного производства товаров, попавших под эмбарго, и экспорт инновационных, в том числе экологически чистых, продуктов. По словам генерального директора ООО “Валио” К. Финска, “российский ассортимент Valio на сегодняшний день насчитывает более 120 позиций, а в некоторых категориях, по оценкам компании, она является лидером" [Молочная промышленность, 2018: 45].

Немаловажным фактором успеха остаётся лояльность потребителей, в первую очередь в Санкт-Петербурге и Москве. В этих городах бренд Viola является лидером рынка в денежном и объемном выражении в сегментах плавленых сыров в “ванночках" и в “треугольниках". На этом основании плавленому сыру Valio была присуждена Премия “Товар года - 2018”3.

Более $60 \%$ продукции Valio продаёт напрямую через крупные торговые сети, остальное реализуют рестораны и кафе, торговые партнёры-дистрибьюторы [Деловой Петербург, 2016]. Сегодня потребители имеют возможность заказа продукции с сайта компании, дополнившем традиционные каналы дистрибьюции.

Оценивая свои перспективы, компания полагает, что молочные продукты составляют часть необходимого рациона многих россиян. При этом можно согласиться с мнением Р. Леннстрёма, экс-генерального директора ООО "Валио” о том, что

\footnotetext{
1 “Вощажниково" увеличило реализацию молока на 4,2\%, URL: http://apknews.su/news/212/2320 (дата обращения: 28.03.2019).

2 OOO “Валио”, URL: www.spark-interfax.ru (дата обращения: 28.03.2019).

${ }^{3}$ Viola - лидер рынка и шестикратный лауреат премии “Товар года”, URL: https://www.valio.ru/press/news/viola-lider-rynka-i-shestikratnyy-laureat-premii-tovar-goda/ (дата обращения: 28.03.2019).
}

Современная Европа, 2019, №3 
люди готовы платить за качество, и у российских потребителей сложились ассоциации качества и экологической чистоты продуктов Valio ${ }^{1}$.

Будущеe Valio в России связано с реализацией стратегии концентрации на премиальном и среднеценовом сегментах. В условиях усиления конкуренции со стороны локализовавших производство более крупных международных игроков (Danone, PepsiCo, Hochland, Campina) для удержания позиций на российском рынке потребуются дальнейшие инвестиции, использование конкурентных преимуществ дифференциации и вывода новинок.

\section{Nokian Tyres ${ }^{2}$}

Концерн Nokian Tyres - один из крупных разработчиков и производителей шин для легковых автомобилей, коммерческой тяжёлой техники и грузовых автомобилей. На мировом рынке он известен как производитель шин премиум-класса, являясь лидером в этом сегменте в Северной Европе. Входящее в Nokian Tyres розничное подразделение Vianor отвечает за сбыт и сервисное обслуживание продукции по франчайзинговым соглашениям с дистрибьютерами. В 2018 году чистая выручка концерна в 62 странах мира составила 1,6 млрд евро, численность сотрудников $-4,8$ тыс. $^{3}$

История Nokian Tyres началась в 1898 г. с основания Финского резинового завода. С 1932 г. производятся автомобильные шины (в том числе с 1934 г. - зимние). В 1988 г. Nokian Tyres выделился из Nokia Ab в качестве самостоятельной компании в ходе масштабной реорганизации, когда последняя освобождалась от непрофильных видов деятельности с целью концентрации на своей ключевой компетенции - мобильной связи.

В настоящее время производственные мощности концерна Nokian Tyres расположены в Финляндии и под Санкт-Петербургом во Всеволожске. Среди причин выбора России для создания производственной площадки - привлекательность российского рынка шин, на тот момент развивавшегося ускоренными темпами, обусловленными общими благоприятными экономическими условиями. Производство в России давало возможность получать экономию за счёт более низких производственных затрат по сравнению с Финляндией или другими европейскими странами. Компания учитывала возможность найма квалифицированной рабочей силы из Петербурга и преимущества инвестиционного климата Ленинградской области по сравнению с городом. Являясь крупным инвестором и создавая новые рабочие места, Nokian Tyres пользуется налоговыми льготами согласно действующим в Ленинградской области законам ${ }^{4}$.

Выпуск продукции в России начался в 2005 г. Первая очередь завода во Всеволожске была рассчитана на производство 2 млн шин в год. Впоследствии концерн, инвестируя в новые производственные линии, превратился в крупное современное автоматизированное предприятие полного цикла с потенциальной мощностью 17 млн шин.

\footnotetext{
${ }^{1}$ Valio: Россия занимает важное место в будущем нашего бизнеса, URL: https://www.valio.ru/press/publications/valio-rossiya-zanimaet-vazhnoe-mesto-v-budushchemnashego-biznesa/ (дата обращения: 28.03.2019).

2 Авторы статьи выражают благодарность Серафиме Николаевне Хаткевич, предоставившей значительную часть материалов для анализа деятельности концерна Nokian Tyres.

${ }^{3}$ Официальный сайт Nokian Tyres, URL: https://www.nokiantyres.com (дата обращения: 28.03.2019).

4 Льготы для инвесторов, URL: http://lenoblinvest.ru/investitsii-v-promyshlennost/lgoty-isubsidii-dlya-promyshlennosti/lgoty-dlya-investorov (дата обращения: 28.03.2019).
}

Современная Европа, 2019, №3 
Завод в России специализируется на производстве летних и зимних шин для легковых автомобилей и внедорожников под брендом Nokian, составляющих сегодня 85\% совокупного выпуска этой линейки концерна. О значимости российского производства для Nokian Tyres говорит факт, что только в 2018 г. оно обеспечивало три четверти общего объёма продаж концерна. Nokian Tyres является крупным работодателем, предоставившим рабочие места 1574 сотрудникам (на конец 2018 г.). По версии HeadHunter, компания входит в топ - 15 работодателей России и в топ 2 в Северо-Западном Федеральном округе ${ }^{1}$. Шины с завода во Всеволожске поставляются более чем в 40 стран. Nokian Tyres включён в первую сотню экспортёров России, являясь при этом одним из крупнейших поставщиков потребительских товаров ${ }^{2}$. Ранее, по итогам конкурса Минпромторга РФ Nokian Tyres был признан Лучшим российским экспортёром 2013 г. по нефтехимической промышленности ${ }^{3}$.

Причины впечатляющих показателей экспорта в этот период связаны с рядом факторов. В 2013 г. в отчёте концерна среди угроз продаж в России отмечались негативные прогнозы по динамике ВВП, девальвация рубля, сопутствующая инфляция, рост процентных ставок, снижение покупательской способности. Прослеживалась тенденция смещения потребительского спроса с премиального сегмента к “бюджетному” и среднеценовому. В 2016 г. доля последнего составляла 65\% объёма продаж легковых шин ${ }^{4}$.

Одновременно более низкие издержки, связанные с локализацией производства в России и поставками значительной доли сырья с внутреннего рынка 5 (с оплатой в рублях), и валютные доходы от поставок готовой продукции на внешние рынки в условиях девальвации обусловили повышение роли экспорта продукции, произведённой российским подразделением. Его доля увеличилась с 55\% от общего объёма производства завода в Всеволожске в 2014 г. до 70\% в 2016 г.

Однако эта тенденция впоследствии прервалась, доля экспорта снизилась в 2017 г. до 64\% и до 62\% в 2018 г. [Nokian Tyres Financial Review, 2014-2018]. Причина в улучшении ситуации на российском рынке новых легковых автомобилей, который после нескольких лет отрицательной динамики вырос на $12 \%$ и 13\% в 2017-2018 гг. соответственно. В свою очередь, российский шинный рынок после сокращения в 2013-2016 гг., вырос на 20,5\% в 2017 г. ${ }^{6}$ Рост продолжился и в 2018 г., составив 10\% ${ }^{7}$. Это нашло отражение в росте чистой выручки Nokian Tyres

${ }^{1}$ Официальный сайт Nokian Tyres, URL: https://www.nokiantyres.com (дата обращения: 28.03.2019).

${ }^{2} 200$ крупнейший компаний-экспортеров России по итогам 2017 года, URL: https://expert.ru/dossier/story/rating200 (дата обращения: 28.03.2019).

${ }^{3}$ Nokian Tyres в России: 10 главных событий за 10 лет, URL: https://www.nokiantyres.ru/onokian-tyres/press-reliz/nokian-tyres-v-rossii-10-glavnyh-sobytij-za-10-let/_дата обращения: 28.03.2019)

4 Российский рынок шин для легковых автомобилей может вырасти на 7\%, URL: https://www.autostat.ru/news/30315/ (дата обращения: 28.03.2019).

5 Локализация сырья по видам колеблется от 40 до 80 \%, только натуральный каучук полностью импортируется. [Автомобильный журнал “ДВИЖОК”, июнь 2016, с. 12].

6 Российский рынок шин на подъеме, URL: http://ai-media.ru/news/rossijskij-rynok-shin-napodjome (дата обращения: 28.03.2019).

${ }^{7}$ Компания Nokian Tyres в 2018 году укрепила лидерские позиции на российском шинном рынке, URL: https://www.nokiantyres.ru/o-nokian-tyres/press-reliz/kompaniya-nokian-tyres-vСовременная Европа, 2019, №3 
на российском рынке (за 2017 г. - на 50\% и за 2018 г. - на 15\%) и повышении её доли в совокупном показателе концерна в 2018 г. до 19\% (105 млн евро) ${ }^{1}$.

Хорошей новостью для Nokian Tyres стало и решение в его пользу Верховного административного суда Финляндии о возврате излишне уплаченных налогов с дохода российской дочерней компанией согласно проведённому финскими налоговыми органами аудиту трансфертного ценообразования за период 2007-2010 гг. Вывод аудита о том, что концерн пытался получить выгоду, заключая внутрифирменные сделки между финской материнской и российской дочерней компаниями по более низкой, чем рыночная цене, был признан несостоятельным.

По итогам 2016-2017 гг. концерн находился по выручке в тройке лидеров финских компаний, ведущих бизнес в России, и занимал второе место по объёму инвестиций (таблица 1). На эти показатели оказали влияние выгодное месторасположение в регионе с развитой инфраструктурой, доступ к клиентам Европы и Северной Америки по морским маршрутам, близость целевых рынков сбыта (“столичных" российских регионов и европейских стран, прежде всего Северной Европы), ёмкость внутреннего рынка. Свою роль сыграло и восприятие российскими потребителями шин Nokian Tyres как продукции финского производителя, предлагающего инновационные шины высокого качества.

Перспективы Nokian Tyres в России в целом выглядят благоприятно, несмотря на определённые угрозы для экспорта в связи с предстоящим в 2020 г. вводом завода Nokian Tyres мощностью 4 млн шин в год в США и обостряющуюся конкуренцию среди международных производителей шин, локализовавших производство в России (Michelin, Pireli, Continental, Yokohama). Прогноз по росту продаж в России новых легковых автомобилей в 2019 г. на уровне $10-12 \%$ позволяет надеяться на увеличение продаж зимних шин. Необходимо учесть и устойчивый спрос на шины на так называемом вторичном рынке (замена шин на новые требуется в среднем раз в 3-4 г.).

\section{Кейс “риаско”: Kesko}

Одним из крупных представителей финского торгового бизнеса, который почти полтора десятилетия активно работал на российском рынке, является K-Group (холдинг Kesko). Холдинг возник в 1940 г. в результате слияния 4 оптовых региональных компаний. У K-Group 1800 магазинов в Финляндии, Швеции, Норвегии, Польше, странах Балтии и Республике Беларусь. Чистая выручка в 2016 г. составила 10,8 млрд евро, из которых $22 \%$ приходилось на зарубежную деятельность. Численность сотрудников Kesko в 2017 г. - 22 тыс. человек, из них 52\% работали на внешних рынках ${ }^{2}$.

В России K-Group последовательно расширяла бизнес в такие сегменты розницы, как товары для дома и ремонта, спортивные товары и продукты питания. При выходе на рынок использовались различные формы. Среди них покупка магазинов сети строительных товаров “Строймастер”, договор с Intersport International и компанией Melovest о покупке доли сети магазинов спортивных товаров и развитием

2018-godu-ukrepila-liderskie-pozicii-na-rossijskom-shinnom-rynke_(дата обращения:

28.03.2019).

${ }^{1}$ Nokian Tyres Annual Reports. 2017-2018, URL:

https://www.nokiantyres.com/company/publications/annual-reports/ (дата обращения: 28.03.2019).

2 Официальный сайт Kesko, URL: https://www.kesko.fi/en/ (дата обращения: 28.03.2019). Современная Европа, 2019, №3 
их бизнеса по франшизе, инвестиции в открытие новых магазинов во всех сегментах бизнеса холдинга Kesko в России.

Rautakesko Ltd. начала активные операции в России, купив в 2005 г. за 19,6 млн евро пять магазинов сети "Строймастер", занимавшей в то время пятую часть петербургского розничного рынка DIY (Do It Yourself) [Деловой Петербург, 2005]. Проведя в 2006 г. ребрендинг сети, она стала развивать в России сеть гипермаркетов товаров для дома и ремонта К-Раута. К этому времени холдинг Kesko уже имел опыт продажи стройматериалов своей дочерней компании ZAO Kestroy, Russia. Став также владельцем сети “Строймастер”, Kesko получил возможность использовать её опыт и знание рынка, налаженные логистику и связи с поставщиками для расширения деятельности в России. В первый период деятельности Kesko одновременно инвестировал в строительство гипермаркетов K-Rauta. К началу 2018 г. холдинг владел 14 торговыми точками (8 в Петербурге, 3 в Москве, по одной в Калуге, Ярославле и Туле).

Инвестиции и маркетинг помогли K-Rauta динамично развиваться. Так ежегодные темпы прироста выручки в 2007-2012 гг. составляли двузначные цифры (таблица 2). Однако с 2013 г. показатели сети кардинально изменились, чистая выручка стала снижаться. При этом динамика была хуже рынка российского рынка строительных и отделочных материалов в целом. В 2017 г. по отношению к 2016 г. чистая выручка K-Rauta увеличилась на $6 \%$, но в то же время российский рынок DIY вырос больше - на 9,6\% [РБК, 2018].

На деятельность холдинга в рассматриваемом сегменте оказал влияние целый ряд внешних факторов. Среди них жёсткая конкуренция со стороны международных игроков и крупных российских сетей. Потерю лидирующих позиций на петербургском рынке компания не смогла восполнить расширением деятельности в регионах, куда она пришла позже других крупных игроков. Замедление темпов ввода жилой и коммерческой недвижимости, увеличение предложения на первичном рынке квартир с отделкой обусловило сдвиг спроса на строительные и отделочные материалы из розничного сегмента в оптовый. Снижению спроса способствовали колебания валютного курса рубля, высокие проценты по ипотеке, негативные ожидания потребителей относительно ситуации в экономике в целом. В итоге в 2018 г. Kesko принял решение о продаже сети магазинов K-Rauta французской Leroy Merlin.

K-Rauta, Russia

Таблица 2.

\begin{tabular}{|l|c|c|c|c|c|c|c|c|c|}
\hline Показатели & 2006 & 2007 & 2008 & 2011 & 2012 & 2013 & 2015 & 2016 & 2017 \\
\hline $\begin{array}{l}\text { Чистая } \\
\text { выручка, } \\
\text { млн евро }\end{array}$ & 102 & 178 & 203 & 237 & 284 & 272 & 250 & 174 & 184 \\
\hline $\begin{array}{l}\text { Изменение } \\
\text { чистой вы- } \\
\text { ручки в евро } \\
\text { к предыду- } \\
\text { щему году, \% }\end{array}$ & $+47,0$ & $+34,9$ & $+16,4$ & $+19,6$ & $-4,2$ & $-8,2$ & $-9,5$ & $+6,0$ \\
\hline
\end{tabular}

Источник: составлено по данным Kesko, URL: https:/www.kesko.fi/en/investor/financialinformation-and-publications/Annual-reports/ (дата обращения: 28.03.2019). 
C 2011 г. холдинг Kesko развивал бизнес в сегменте торговли спортивными товарами. Начав с покупки 80\% сети Intersport, в 2012 г. он выкупил оставшуюся часть [Ведомости, 2016]. Подразделение Intersport Finland Ltd, управляя сетью спортивных товаров одноименного бренда и в России, планировало реформирование бизнес-процессов в рамках новой концепции деятельности сети, включая закрытие неприбыльных магазинов (таблица 3 ).

Одновременно к 2019 г. планировалось увеличить число магазинов под брендами Intersport Run \& Fit для профессиональных спортсменов и The Athlete`s Foot, предлагающих спортивную одежду и обувь на каждый день [КоммерсантЪ, 2015], с меньшей площадью и более узким ассортиментом. Компания ориентировалась на повышение внимания к образу жизни и здоровью в поведении покупателей.

Intersport, Russia

Таблица 3.

\begin{tabular}{|l|c|c|c|c|c|c|}
\hline Показатели & 2011 & 2012 & 2013 & 2014 & 2015 & 2016 \\
\hline $\begin{array}{l}\text { Чистая выручка, } \\
\text { млн евро }\end{array}$ & 7 & 28 & 18 & 15 & 12 & н/д \\
\hline $\begin{array}{l}\text { Изменение чистой } \\
\text { выручки в евро к } \\
\text { предыдущему году, \% }\end{array}$ & 36 & 29 & 21 & 19 & 18 & 16 \\
\hline $\begin{array}{l}\text { Количество магази- } \\
\text { нов на конец года }\end{array}$ & +30 & $-36,6$ & $-17,6$ & $-17,0$ & н/д \\
\hline
\end{tabular}

Источник: составлено по данным Kesko, URL: https://www.kesko.fi/en/investor/financialinformation-and-publications/Annual-reports/ (дата обращения: 28.03.2019).

После первых двух успешных лет деятельности сети Intersport на российском рынке, с 2013 г. её чистая выручка постоянно снижалась. В 2015 г. доля Intersport составляла менее $0,6 \%$ [Ведомости, 2016], существенно уступая крупнейшему конкуренту в данном сегменте - сети “Спортмастер”. В феврале 2016 г. Kesko принял решение о продаже Intersport в России.

Ещё одним сегментом, где Kesko предпринял усилия по выходу на российский рынок, стала продуктовая розница. В декабре 2012 г. в Санкт-Петербурге был открыт первый магазин K-Ruoka. Число магазинов сети постепенно увеличилось до десяти гипермаркетов и одного супермаркета, расположенных в Санкт-Петербурге и Ленинградской области (таблица 4). Привлекательность сегмента для Kesko была обусловлена потенциальным спросом. Россия является крупнейшим рынком продовольственной розницы в Европе ${ }^{1}$.

Продуктовый ассортимент K-Ruoka во многом состоял из товаров западного производства, в первую очередь финского происхождения. Вместе с тем аналогичные продукты потребители могли найти и в других магазинах Санкт-Петербурга. Ситуацию усугубило введённое Россией эмбарго на поставку целого ряда продуктов питания из стран Запада, составляющих значительную часть типичного магазина K-Ruoka. Выход в Россию был осуществлён позже схожей по формату финской

${ }^{1}$ Top 20 European grocery markets in 2022, URL:

https://www.igd.com/research/retail/article/t/european-grocery-retail-market-to-be-worth-2289-

billion-by-2022/i/18614 (дата обращения: 28.03.2019).

Современная Европа, 2019, №3 
K-Ruoka, Russia

Таблица 4.

\begin{tabular}{|l|c|c|c|c|}
\hline & 2013 & 2014 & 2015 & $\begin{array}{c}2016 \\
\text { (январь - ноябрь) }\end{array}$ \\
\hline $\begin{array}{l}\text { Чистая выручка, } \\
\text { млн евро }\end{array}$ & 71 & 103 & 107 & 105 \\
\hline $\begin{array}{l}\text { Изменение чистой выручки в } \\
\text { евро к предыдущему году, \% }\end{array}$ & 4 & 5 & 9 & $-1,9$ \\
\hline $\begin{array}{l}\text { Количество магазинов на ко- } \\
\text { нец года }\end{array}$ & $+46,7$ & $+3,1$ & 11 \\
\hline
\end{tabular}

Источник: составлено по данным Kesko, URL: https://www.kesko.fi/en/investor/financialinformation-and-publications/Annual-reports/ (дата обращения: 28.03.2019).

сети Prisma, занявшей более выгодные торговые точки в центральных районах города (в отличие от “спальных" у K-Ruoka) и проводившей более агрессивную маркетинговую политику. После четырёх лет, не получив планируемых результатов (в 2015 г. убытки сети K-Ruoka составили 14 млн евро), холдинг принял решение о выходе своей продовольственной сети из России. В ноябре 2016 г. все магазины K-Ruoka были проданы компании “Лента". По словам президента Kesko M. Хеландера, решение об уходе с российского рынка обусловлено тем, что инвестиции в России “не оправдали ожиданий, а экспансия за пределы Петербурга и Москвы потребовала бы значительных дополнительных инвестиций”"

Рассматривая деятельность Kesko в России, отметим его вклад в создание рабочих мест. Их число в России составляло 1278 человек на конец 2017 г. (8\% общего числа сотрудников холдинга $)^{2}$.

\section{Bbыводы}

Факторы успеха крупных финских компаний в России непосредственно связаны с адаптацией к изменяющимся условиям и локализацией хозяйственной деятельности. В число лидеров выходят те, кто умело сочетает конкурентные преимущества производства в России со своими внутренними специфическими ресурсами и возможностями, грамотно реагируя на отраслевую конкуренцию и институциональные особенности ведения бизнеса в РФ. Инвестиции в расширение деятельности позволили целому ряду финских компаний адаптироваться к спросу российских потребителей. Об этом свидетельствуют данные о динамике выручки и инвестициях крупных финских компаний в России. Это подтверждают и проанализированные более детально кейсы компаний из различных сфер бизнеса.

В то же время только за 2018 г. несколько крупных финских компаний ушли с российского рынка. Среди них представители сферы производства (производитель специальных сталей и металлоконструкций Ruukki Rus), медицинских услуг (сети частных клиник “Ава-Петер” и “Скандинавия”). Мировая практика даёт целый ряд примеров ухода крупных международных розничных сетей с отдельных национальных рынков. “Wall Mart” ушёл из Германии, “Marks \& Spencer” свернул дея-

${ }^{1}$ Kesko's Annual Report 2017, URL: https://www.kesko.fi/en/investor/financial-information-andpublications/Annual-reports/ (дата обращения: 31.01.2019).

2 Там же. 
тельность в Китае, Франции и ряде других стран. В число покинувших в последние годы российский розничный рынок иностранных игроков этой сферы (Castorama, C\&A, Gerry Weber, Media Markt и другие) вошёл и холдинг Kesko.

Вместе с тем в практике международного бизнеса есть примеры повторного выхода на российский рынок. Назовем возвращение бренда чешской обуви Bata, aмeриканского бренда обуви, сумок и аксессуаров Coach, немецкого бренда одежды и аксессуаров Orsay, британского бренда дизайнерской одежды Alexander McQueen [Профиль, 2018]. Будущее покажет, войдут ли в этот список финские компании.

\section{Список литературы}

Бухвалов А.В., Алексеева О.А. (2015) Стратегии международных компаний на развивающихся рынках: влияние глобализации и опыт локализации производства, Российский журнал менеджмента, T. 13, № 2, с. 149-170.

Волков А.М. (2016) Экономические отношения России с Финляндией на современном этапе, Вестник Института экономики Российской академии наук, №5, с. 165-181.

Зашев П.Р., Трофименко О.Ю. (2017) Экспорт финских малых и средних предприятий в Россию: современные тенденции, проблемы и перспективы, Международная торговля и торговая политика, № 2 (10), c. 43-57.

Кархунен П., Косонен Р. (2009) Факторы, определяющие формы участия финских инвесторов в компаниях из стратегических отраслей российской экономики, Экономическая наука современной России, № 4 (47), c. 127-140.

Ковалев В.Р. (2014) Трансграничное сотрудничество между регионами России и Финляндии, Журнал правовых и экономических исследований, № 4 с. 156-162.

Маршан А.В. (2004) Опыт интернационализации финской корпорации KONE, Российский журнал менеджмента, Т. 2, № 1, с. 151-161.

Пискулов Ю. (2013) Традиции российско-финляндской торговли, Международная экономика, № 5 , c. $33-43$.

Реколайнен Я. (2018) Финские компании пришли в Россию, чтобы остаться, Международная жизнь, № 4, с. 103-109.

Шлямин В.А. (2007) Российско-финляндские экономические отношения. Проблемы и перспективbl, Изд-во Политехнического университета, Санкт-Петербург, Россия, 294 с.

Шлямин В.А. (2015) Российско-финляндское экономическое сотрудничество: прошлое, настоящее, будущее, Вестник Санкт-Петербургского университета, Серия 5, Экономика, вып. 1, с. 122-129.

\section{References}

Buhvalov A.V., Alekseeva O.A. (2015) Strategii mezhdunarodnyh kompanij na razvivayushchihsya rynkah: vliyanie globalizacii i opyt lokalizacii proizvodstva [International companies strategies in emerging markets: globalization impact and experience of production localisation], Rossijskij zhurnal menedzhmenta, vol. 13, no. 2, pp. 149-170.

Volkov A.M. (2016) Ekonomicheskie otnosheniya Rossii s Finlyandiej na sovremennom etape [Economic relations of Russia and Finland at the present stage], Vestnik Instituta ekonomiki Rossijskoj akademii nauk, no. 5, pp. 165-181.

Zashev P.R., Trofimenko O.Yu. (2017) Eksport finskih malyh i srednih predpriyatij v Rossiyu: sovremennye tendencii, problemy i perspektivy [Export of Finnish SMEs to Russia: modern trends, challenges and prospects], Mezhdunarodnaya torgovlya i torgovaya politika, no. 2 (10), pp. 43-57.

Karhunen P., Kosonen R. (2009) Faktory, opredelyayushchie formy uchastiya finskih investorov v kompaniyah iz strategicheskih otraslej rossijskoj ekonomiki [Institutional, Industry-Level and Firm-Level Determinants of Foreign Ownership Strategies: Finnish Investors' Views of Strategic Sectors in Russia], Ekonomicheskaya nauka sovremennoj Rossii, no. 4 (47), no. 127-140.

Kovalev V.R. (2014) Transgranichnoe sotrudnichestvo mezhdu regionami Rossii i Finlyandii [Transborder cooperation in Russian and Finnish regions], Zhurnal pravovyh i ekonomicheskih issledovanij, no. 4, pp. 156162.

Marshan A.V. (2004) Opyt internacionalizacii finskoj korporacii KONE [Internationalisation experience of the Finnish KONE Corporartion], Rossijskij zhurnal menedzhmenta, vol. 2, no. 1, pp. 151-161.

Современная Европа, 2019, №3 
Piskulov Yu. (2013) Tradicii rossijsko-finlyandskoj torgovli [Traditions of the Russian-Finnish trade], Mezhdunarodnaya ekonomika, no. 5, pp. 33-43.

Rekolajnen Ya. (2018) Finskie kompanii prishli v Rossiyu, chtoby ostat'sya [Finish companies came to Russia to stay], Mezhdunarodnaya zhizn', no. 4, pp. 103-109.

Shlyamin V.A. (2007) Rossijsko-finljandskie jekonomicheskie otnoshenija. Problemy i perspektivy. [Russian-Finish economic relations. Problems and perspectives], SPb: Izd-vo Politehnicheskogo universiteta, $294 \mathrm{~s}$.

Shlyamin V.A. (2015) Rossijsko-finlyandskoe ekonomicheskoe sotrudnichestvo: proshloe, nastoyashchee, budushchee [Russian-Finland economic cooperation: past, present, future], Vestnik SanktPeterburgskogo universiteta, Seriya 5, Ekonomika, issue 1, pp. 122-129.

Golikova, V., Karhunen, P. and Kosonen, R. (2011) Subsidiary evolution in a transition economy: Kemira Grow How in the Russian fertilizer market, Journal of East European Management Studies, vol. 16, no. 1, pp. 9-30. Karhunen P., Kosonen R. (2013) Strategic responses of foreign subsidiaries to host country corruption: The case of Finnish firms in Russia, Critical Perspectives on International Business 9 (1/2), pp. 88-105.

Larimo J., Huuhka Ari (2007) Internationalization of the Biggest Finnish and Swedish Retailers in the Baltic States and Russia, Journal of East-West Business, vol. 13, no. 1, pp. 63-91.

Liuhto K. (2011) The EU-Russia Innovation Cooperation: Some Experiences Emerging from FinnishRussian Innovation Collaboration, Journal of East-West Business, Apr-Sep, vol. 17, issue 2/3, pp. 156-169.

Liuhto K., Sutyrin S. and Blanchard J.-M.F. (eds) (2017) The Russian economy and foreign direct investment, Routledge, NY, USA, $276 \mathrm{p}$.

Salmi, A., Heikkilä K. (2015) Managing relationships with public officials - A case of foreign MNCs in Russia, Industrial Marketing Management 49, pp. 22-31.

Sutela P. (2007) The Folklore of Finland's Eastern Trade, Europe-Asia Studies, Jan, vol. 59, issue 1, pp. 137-162.

Sutyrin S.F., Vorobieva I.V. (2017) "Russian Consumers' behavior: In search of balance between national uniqueness and universal mainstream”, in: Marin A. Marinov (ed.) Research Handbook of Marketing in Emerging Economies, Edward Elgar Publishing, Cheltenham, UK, pp. 222-240.

Zashev P., Sutyrin S.F. (2012) Intangible Barriers to Russian Imports: A Case of Finnish SMEs Entering RF Markets, Region: Regional Studies of Russia, Eastern Europe, and Central Asia, vol. 1, no. 1, pp. 131153.

Zimin D. (2012) How Can Foreign Companies Influence Russia's Economic Course? The Cases of Finnish Firms Fortum and Neste, Post-Soviet Affairs, Apr-Jun, vol. 28, issue 2, pp. 209-231.

\section{Large Finnish Companies in the Russian market}

Authors: Sutyrin S., Doctor of Sciences (Economics), Professor, Head of the World Economy Department, Saint Petersburg State University. Address: 7/9, Universitetskaya nab., St. Petersburg, Russia, 199034. E-mail: s.sutyrin@hotmail.com

Vorobieva I., Candidate of Sciences (Economics), Associate Professor of the World Economy Department, Saint Petersburg State University. Address: 7/9, Universitetskaya nab., St. Petersburg, Russia, 199034. E-mail: irinavorob@mail.ru

Abstract. The paper deals with the results of the study of large Finnish companies doing business in Russia. The authors analyze main indicators of the top- 15 firms operating in different sectors of the Russian economy as well as the most significant factors influencing their performance. The purpose is to define strategic decisions made by the companies in recent years and to discuss their possible prospects. The findings show the utmost significance for large Finnish companies to adjust to changing economic and political environment. The companies who find the proper balance in combining competitive advantages of local production with their own internal specific resources, promptly responding to the challenges of intra-industry competition are among the leaders. Investments in the expansion of major local activities tend to allow the Finnish firms to satisfy the changing demand of Russian consumers. Case studies scrutinize two successful companies and one that had to leave the market.

Key words: Finland, Russia, large business, foreign market entry, foreign trade, foreign direct investments, factors of success, market exit.

DOI: http://dx.doi.org/10.15211/soveurope32019125138

Современная Европа, 2019, №3 